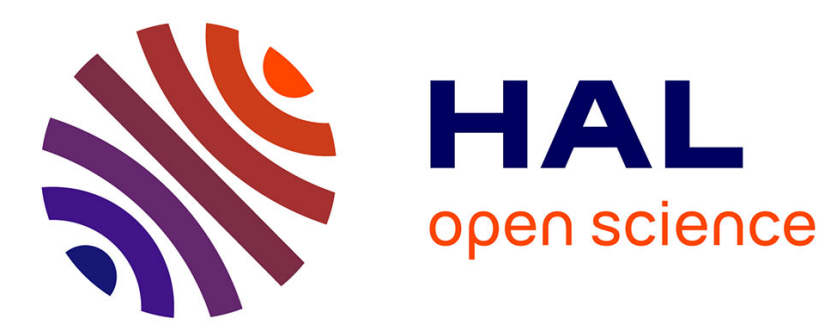

\title{
Riveted assembly modelling: Study and numerical characterisation of a riveting process
}

\author{
V. Blanchot, Alain Daidié
}

\section{To cite this version:}

V. Blanchot, Alain Daidié. Riveted assembly modelling: Study and numerical characterisation of a riveting process. Journal of Materials Processing Technology, 2006, 180 (1-3), pp.201-209. 10.1016/j.jmatprotec.2006.06.005 . hal-02120230

\section{HAL Id: hal-02120230 \\ https://hal.science/hal-02120230}

Submitted on 5 May 2019

HAL is a multi-disciplinary open access archive for the deposit and dissemination of scientific research documents, whether they are published or not. The documents may come from teaching and research institutions in France or abroad, or from public or private research centers.
L'archive ouverte pluridisciplinaire HAL, est destinée au dépôt et à la diffusion de documents scientifiques de niveau recherche, publiés ou non, émanant des établissements d'enseignement et de recherche français ou étrangers, des laboratoires publics ou privés. 


\title{
Study and numerical characterisation of a riveting process
}

\author{
V. Blanchot ${ }^{1}$, A. Daidie ${ }^{2}$ \\ ${ }^{1}$ Université Claude Bernard Lyon1 - IUT B, GMP, 17 rue de France, 69627 Villeurbanne, France \\ URL: iut-b.univ-lyon1.fr $\quad$ e-mail: vincent.blanchot@iutb.univ-lyon1.fr; \\ ${ }^{2}$ INSA de Toulouse - LGMT, 135 avenue de Rangueil, 31077, Toulouse cedex 4, France \\ URL: www.meca.insa-toulouse.fr/lgmt/ e-mail: alain.daidie@insa-toulouse.fr;
}

ABSTRACT: The work presented in this paper fits in with the riveting process by dealing with a large practical case of riveted assemblies as often encountered in industry and in civil aeronautics field. After an introduction to the riveting process itself, this paper incorporates analysis of strains and stresses located in the plates and rivet in post-riveting. The objectives of this study are to identify certain special characteristics, the consequences they entail for resistance tests, and finally to improve knowledge about the riveting process and behaviour of riveted links.

Key words: Rivet, Riveted assembly, Riveting process, Numerical simulation, Residual stresses

\section{INTRODUCTION}

In mechanical design, the use of rivets for assembling plates is becoming a standard procedure. However, riveted links are often the most sensitive area, speaking in terms of mechanical resistance in an overall structure. For instances of static calculation, it is safe and accurate to use any of the empirical calculation methods as proposed by the EUROCODE [1] or on the Machinery Handbook [2]. Unfortunately, these methods appear to be inadequate in some instances of crash FE simulation, especially in civil aeronautics or more simply for some cases of structural certification dynamic calculation. Since it is necessary to simulate and characterise the behaviour of the riveted link in tensile load and shearing [3], it is important to take account of the initial riveting phase. The first stage therefore involves studying the riveting process itself. After an introduction to the riveting process itself, this paper incorporates analysis of strains and stresses located in the plates and rivet in postriveting. Studies have already been conducted by Langrand [4] on riveted assemblies in aeronautics but with a more or less standard rivet, using the Pam-Stam calculation code. The objectives of this study, which is based on the Radioss calculation code, are to identify certain special characteristics and the consequences they entail for future resistance tests.

\section{STUDIED MODEL}

\subsection{Geometry}

The rivet's head is vertically blocked by a plug along the $\mathrm{Z}$ direction (Fig. 1). When the hammer crushes the rivet's low part, it makes an impact according to a sine wave low in the $\mathrm{Z}$ direction. The body is repulsed over $2.5 \mathrm{~mm}$.

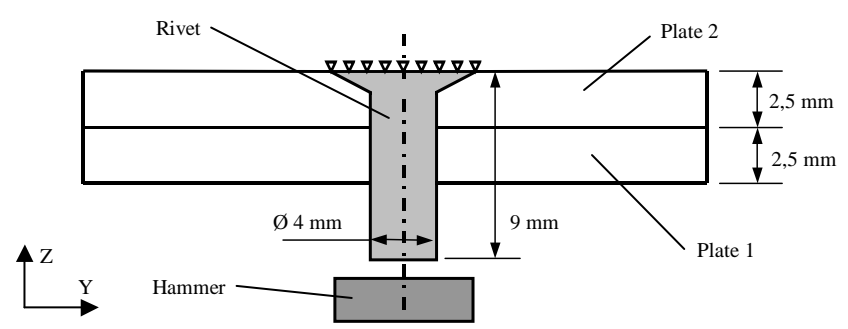

Fig. 1. Studied model

\subsection{Material behaviour law}

For the considered case, the hammer is made of XC100 steel and the rivet of titan T40. Plate 1 is made of aluminium and plate 2 of Titan TA6V. The behaviour law selected for each solid is the JohnsonCook strength model [5], which is elastic-plastic. The plastic limit is free from damage. The plastic stress-strain characteristics of the law derive from the true stress-strain curve itself taken from the engineering stress-strain curve. Riveting is performed at ambient temperature $\left(20^{\circ} \mathrm{C}\right)$. 


\subsection{Presented models}

Some simulations, as the one done with tensile load, have the particularity of being "axisymmetric" models. A model using the symmetric Radioss option was created for those cases. For other cases, such as shearing load or tensile and shear combination (mixed load), the load ceases to be axisymmetric, hence it is necessary to use a 3D complex semi-model for coherent results.

The upcoming paragraphs briefly describe these two riveting models (axisymmetric and 3D) and present the calculation results.

\section{AXISYMMETRIC MODEL}

\subsection{Meshing}

For axisymmetric models, only one semi-section is considered. During calculation, the software uses a number of axisymmetrical equations

The rivet element size is refined according to the rivet strain, leading to adopting very small elements. The meshing is free in the head zone and mapped in the body zone. As the plates are relatively free from deformation, the plate elements are larger. However, the element ratio of element size for surfaces facing each other must be equal (where there is contact between the two parts) for good interface behaviour.

\subsection{Boundary conditions}

- the $\mathrm{Z}$ translation of rivet nodes is blocked in the top plane to simulate the plug

- the hammer's nodes in the bottom plane follow a sinusoidal displacement law in the $\mathrm{Z}$ direction (period: 1ms ; amplitude: 2,5 mm)

\subsection{Interfaces}

Interfaces simulating contacts and interactions between solids are defined as follows:

- interface between hammer and rivet

- interface between rivet and plates

- interface between plates

Note: a sensitivity study, not presented here, shows that the friction coefficient value (between 0 and 0.2 for these 3 interfaces) has no significant influence on the results.

\subsection{Results analysis}

\section{4.a Strain study}

Figure 2 shows the successive steps in rivet strain according to the deformation real time (ms).
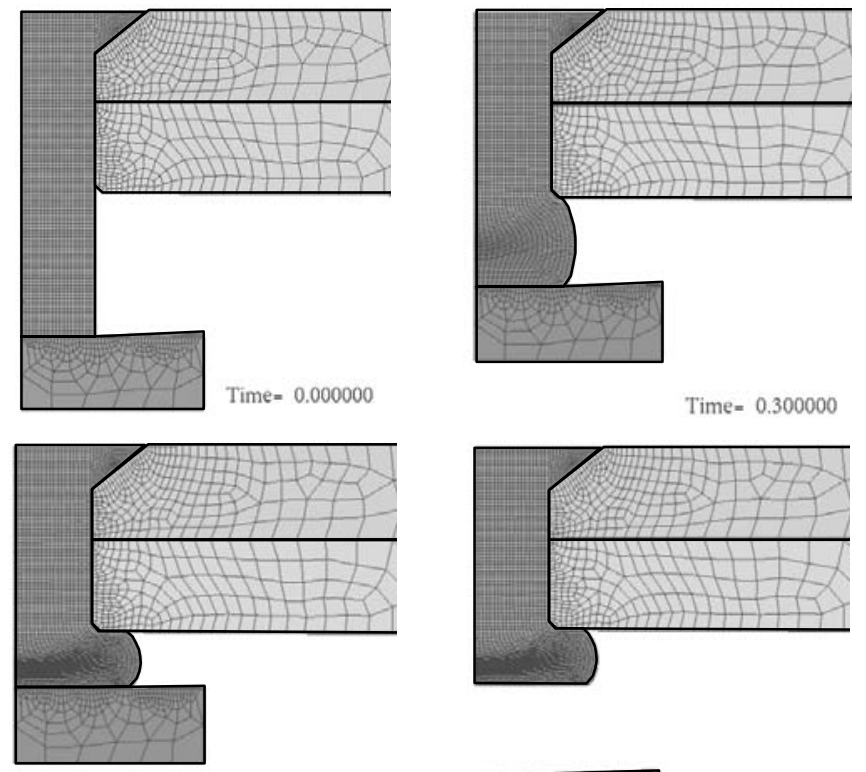

Time= 0.500002

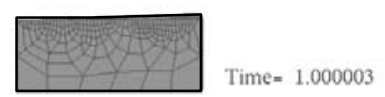

Fig. 2. Evolution of the rivet strain

After a first calculation, the rivet elements are compressed and reach fracture strain. However, the rivet is mainly in hydrostatic compression, so elements should not break. Fracture strain should in theory be taken into account just for tensile load and not for compression load as in our case. Indeed, the Radioss calculation code fails to distinguish variations in height between compression and tensile strain. This explains why the rivet elements have an infinite elongation and an infinite break stress to improve stability of the model during the riveting phase.

\section{4.b Riveting stress}

Table 1 shows axial stress ( $Z$ direction) of the hammer/rivet interface.

Table1. Riveting stress

\begin{tabular}{lllll}
\hline Hammer displacement (mm) & 0 & 0.33 & 0.59 & 2.5 \\
\hline Experimental stress (N) & 0 & 6000 & 9000 & 12300 \\
\hline Simulation stress (N) & 0 & 6086 & 8925 & 12460 \\
\hline Difference (\%) & 0 & +1.43 & -0.83 & +1.3 \\
\hline
\end{tabular}

The analysis displays prominently a good correlation between experimental made by B. Langrand [6] and numerical results. This report vindicates the validity of the simulation. 


\section{4.c Stress analysis}

Only the rivet has exceeded the yield stress, as can be seen in figure 3 . The plates and the hammer are not subjected to plastic strain, even locally. There is therefore no need to consider any calculation instability that would be due to plate or hammer plastification.

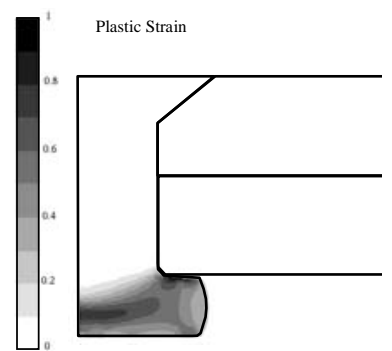

Fig. 3. Plasticity strain ratio

The axial stresses (Fig. 4a) in the plates and the contact pressure between them are negligible (with average value of $30 \mathrm{MPa}$ ).

In the radial direction (Fig. 4b), stresses are higher (average value: -300 $\mathrm{MPa}$ ). This tightening is due to the rivet swelling and stresses can locally reach -600 $\mathrm{MPa}$ in some areas, making the structure prestressed in the radial direction. This pretension in the rivet and in the plates, associated with the stress concentration phenomenon due to the hole, can initiate cracking of the plates and premature weakening of the assembly's mechanical resistance.

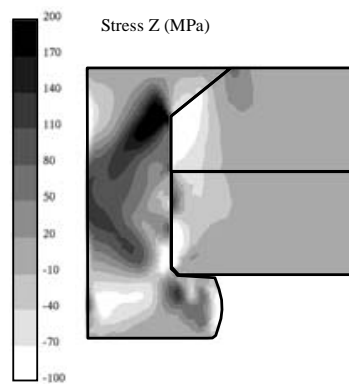

(a) axial stresses

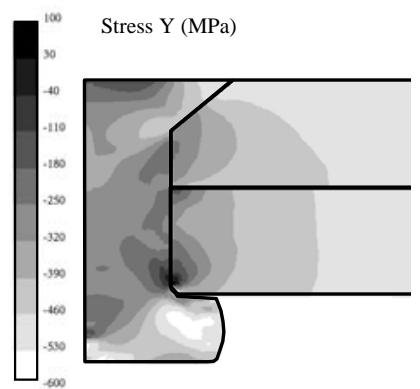

(b) radial stresses

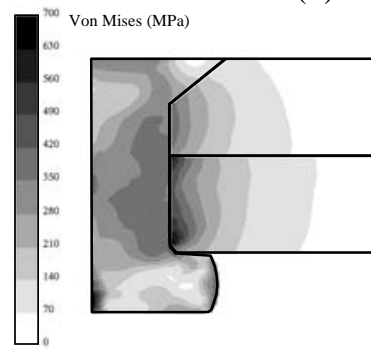

(c) Von Mises stresses

Fig. 4. Residual stresses

The ratio between radial and axial stresses is of 10 . Without external load, radial pretension of the rivet keeps the two plates in position better than with axial pretension. But it remains obvious that when the model is loaded axially, it is axial behaviour that has to be taken into account (as with a bolt).

Von Mises stress (Fig. 4c) is the highest at the rivet/plate interface (value: $700 \mathrm{MPa}$ ). This is mainly due to the rivet tightening and not due to axial pretension as one may think by analogy with bolt bindings.

\section{SYMETRICAL MODEL}

For other cases such as the riveting link break due to shearing load, the axisymmetric model is no longer operative. Therefore, it is necessary to develop a 3D model. Which can be reduced to one half of the 3D geometry due to the plane of symmetry.

\subsection{D meshing}

In this 3D symmetrical model the elements size is considerably increased (Fig. 5) comparing with the 2D axisymmetric model (Fig. 2) in order to reduce calculation time.
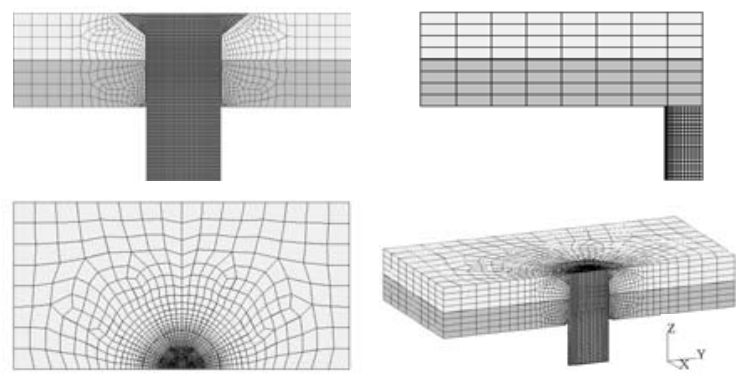

Fig. 5. 3D meshing

\subsection{Boundary conditions and interfaces}

Boundary conditions and interfaces are similar to the ones of $\S 3.2$ and 3.3 .

\subsection{Results analysis}

\section{3.a Strain study}

The 3D model yields reasonably consistent strain results compared to previous models.

\section{3.b Stress analysis}

The final remarks remain the same. A good correlation is obtained comparing with the last model. Residual axial pretensions are not also observed in the plates and rivet (Fig. 6a). In the radial direction (Fig. 6b), the rivet's swelling applies pressure to the plates. 


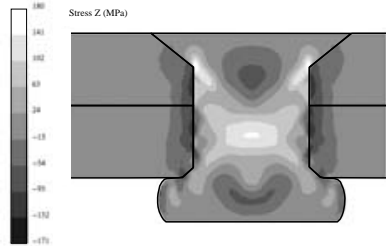

(a) axial stresses

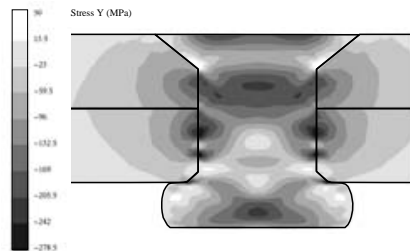

(b) radial stresses
Fig. 6. Residual stresses

\section{DYNAMIC RELAXATION}

The riveting simulation cycle takes about $1 \mathrm{~ms}$, which is quicker than with conventional riveting process, but there is a significant reduction in calculation time. Energy analysis shows that kinetic energy is negligible as compared with internal energy. Quasi-static conditions are proved, justifying the riveting cycle increase to $1 \mathrm{~ms}$. However, one drawback is introduced, with static balance not being reached. This explains why each model is relaxed after riveting calculation (Radioss Dyrel method) to be able to analyse residual strains and stresses.

\section{CORRELATIONS}

Experimental tests have been performed by Langrand [6] for a different rivet geometry than the one presented in this paper. Austruy [7] has conducted some comparative works between three different approaches: these experimental tests, the previously presented study, and a study with Forge2, which is a dedicated simulation tool for metal forming processes. The results show good correlation between numerical and experimental results for some cases of the riveting process, which validates the various proposed numerical models and the riveting process. Any time a test campaign is scheduled to validate the numerical results.

\section{CONCLUSIONS}

The key element of this study is that riveting affects the behaviour of the overall assembly when subjected to an exterior load since the rivet and the plates are in state of pretension subsequent to the riveting operation. Plastic strain does not affect plates and is non-homogeneous in the rivet. The presence of radial pretension can also be observed, whose average value would be difficult to evaluate. Consequently, since it appears difficult to propose an equivalent model based on analytical principles (material resistance, sheet and beam theory, etc.), experimental test results are necessary. The next phase of the study is undergoing further simulations implementing tensile and shearing loads.

Hence, the final goal of this study consists of holding out behaviour diagrams according to different load cases such as tensile loads, shearing loads or combination of the two. Then, a sensitivity study must be conduct for identifying the significant parameters influencing the behaviour and mechanical resistance of the link. The final objective is to extend the scope of this model to other geometries and materials used for rivets and plate.

\section{REFERENCES}

1. EUROCODE 3, Calcul des structures en acier et Document d'Application Nationale, AFNOR, 1992.

2. Machinery's Handbook, 25th edition, Industrial Press Inc., New York, (1996) 1381-1398

3. L. Patronelli, E. Markiewicz, E. Deletombe, B. Langrand, P. Drazetic, Behaviour of riveted joint failure under mixed mode loading, European Journal of Mechanical and Environmental Engineering, 44, (2001) 215-227

4. B. Langrand, E. Deletombe, E. Markiewicz, P. Drazetic, Riveted joint modelling for numerical analysis of airframe crashworthiness, Finite Element in Analysis and Design, 38, (2001) 21-44

5. G. R. Johnson, W.H. Cook, A constitutive model and data for metal subjected to large strains, high strain rates and high temperatures, Proc of $7^{\text {th }}$ Symp. On ballistics, The Hague, The Netherlands, (1993) 541-547

6. B. Langrand, L. Patronelli, E. Deletombe, E. Markiewicz, P. Drazetic, Full scale experimental characterization for riveted join design, Aerospace Science and Technology, 6, (2002) 333-342

7. G. Austruy, Behaviour of riveted assembly in transitory dynamic, DEA training period report, Paul-SabatierToulouse-III University, France (2004). 